\title{
ANÁLISE DA PERCEPÇÃO DOS ESTUDANTES DO ENSINO MÉDIO DA CIDADE DO RIO DE JANEIRO SOBRE AS ABELHAS: QUANTO REALMENTE SABEMOS SOBRE ELAS?
}

Gisele Palmares Gomes da Paixão ${ }^{1}$

Felipe Rodrigo Vivallo Martínez²

Resumo: As abelhas são um dos grupos de insetos mais importantes por participarem ativamente na polinização e, consequentemente, na manutenção de grande parte dos ecossistemas terrestres. Para esse artigo foi avaliado o nível de conhecimento que alunos do ensino médio de diferentes escolas do estado do Rio de Janeiro têm sobre tais insetos - quanto a sua relevância no meio ambiente, ou mesmo quais atividades poderiam contribuir para a manutenção das suas populações. Os resultados obtidos indicam que grande parte dos alunos reconhece a importância das abelhas no meio ambiente, mas desconhecem a riqueza de espécies presentes no país, assim como às ferramentas que podem contribuir com a manutenção das espécies nativas brasileiras.

Palavras-chave: Alunos; Apis melífera; Polinização; Conservação.

1Universidade Veiga de Almeida. E-mail: gisele.palmares@yahoo.com.br 2Laboratório de Hymenoptera HYMN Departamento de Entomologia Museu Nacional. Universidade Federal do Rio de Janeiro. E-mail: fvivallo@yahoo.com 


\section{Introdução}

Os ecossistemas são unidades que englobam complexas, dinâmicas e contínuas interações entre seres vivos e seu ambiente físico, no qual o homem é parte integral (FARID, 2005).

A importância dos estudos sobre o funcionamento da dinâmica de sobrevivência dos seres vivos em relação ao seu ambiente tem aumentado nas últimas décadas (ARRAIS, 2011). Entretanto, o crescimento demográfico e a concentração da população na periferia dos grandes centros urbanos representam, atualmente, uma das grandes ameaças ao equilíbrio ecológico (ORLANDINI, 2009). De acordo com Freitas (2009), na América Latina, os principais problemas para a conservação das abelhas nativas é a falta de informação sobre a taxonomia e diversidade, dinâmica populacional, ou mesmo o impacto das atividades humanas nas diferentes espécies. Devido a tais ações, durante os últimos anos, diversos relatos evidenciaram a diminuição das populações de abelhas (NOCELLI, 2015).

As práticas humanas predatórias têm sido intensamente discutidas por pesquisadores, no entanto, poucos resultados foram obtidos para reverter esse processo. Os problemas ambientais se tornaram preocupação pública quando começaram a ser divulgados pela mídia, principalmente por conta da quantidade de agravantes à saúde ocasionados por eles (PHILIPPI JR.; PELICIONI, 2005).

Em alguns países do continente europeu foi evidenciada a diminuição das abelhas (LAURENT et. al., 2015). De acordo com Engelsdorp et al. (2008), os Estados Unidos perderam, entre 2007 e 2008, aproximadamente um milhão de colônias de abelhas da espécie Apis mellifera. Foram registradas oscilações entre $19 \%$ e $52 \%$ dessa perda em 21 estados americanos, proporcionando, em sua agricultura, sérios prejuízos devido à falta de polinizadores. Fato que poderia estar ligado ao uso irresponsável dos defensivos agrícolas, gerando prejuízos incalculáveis à flora, fauna e ao homem (NOCELLI, 2015). No Brasil, estudos relacionados ao desaparecimento desses insetos também vêm ganhando força.

De acordo com Michener (2007), as abelhas formam um grupo bastante diverso, com cerca de 17.500 espécies descritas distribuídas por todas as regiões do mundo onde existem plantas com flores (angiospermas). Dentre os insetos que visitam as flores, abelhas, tanto solitárias quanto sociais, são usualmente os mais importantes polinizadores de plantas nativas e cultivadas, realizando, desta forma, um papel essencial na conservação dos ecossistemas onde habitam (ROUBIK, 1979). Além disso, estudos feitos por diversos pesquisadores relatam a importância da preservação das condições ambientais e da utilização desses insetos como polinizadores, potencializando a economia de diversas culturas (SOUZA et al., 2007). É importante ressaltar também que cerca de 1/3 da alimentação humana depende direta ou indiretamente de plantas polinizadas ou beneficiadas pela polinização das abelhas (KLEIN et al., 2007). 
Por se tratar de um tema bastante relevante, o presente artigo buscou determinar o nível de conhecimento de uma amostra estudantil sobre a real importância da conservação das abelhas, propondo, posteriormente, metodologias e ferramentas que auxiliem na manutenção e conservação desses insetos.

\section{Material e Métodos}

Procurando estudar o atual nível de conhecimento juvenil sobre a importância das abelhas no meio ambiente, foi realizada uma pesquisa com uma amostra pequena de estudantes do ensino médio, através de um questionário prático e dinâmico, sobre conhecimentos gerais destes insetos. Foram 50 cópias para um igual número de alunos, sendo 25 deles do sexo masculino e 25 do sexo feminino. Esses adolescentes foram abordados na entrada de suas respectivas escolas (tanto da rede pública quanto da rede privada), concentradas nos bairros Andaraí, Tijuca e Vila Isabel, na cidade do Rio de Janeiro.

Cada questionário teve um cabeçalho onde deveria ser preenchido o grau de ensino do estudante e marcação do seu sexo (feminino ou masculino). As perguntas aplicadas, para que respondessem de acordo com a opinião e conhecimento deles, foram as seguintes: 1) Quais são os insetos mais frequentemente encontrados em praças e jardins? 2) Você saberia reconhecer uma abelha? Como? 3) Você acha que as abelhas são importantes para o equilíbrio ecológico? Por quê? 4) Você conhece algum tipo de campanha ou movimento cujo objetivo seja alertar a população sobre a conservação das abelhas? Qual? 5) Você faz alguma atividade para contribuir com a conservação das abelhas? Qual?

Justificativa das perguntas: 1) O aluno deve mencionar entre cinco e dez exemplos de insetos que acredita ser comumente encontrados nos locais indicados acima. 2) $O$ aluno deve indicar quais características permitem reconhecer especificamente algum tipo de abelha. 3) O aluno deverá mostrar se reconhece e compreende a importância das abelhas nos diferentes ecossistemas. 4) $O$ aluno deve responder se conhece algum tipo de ação ou campanha que esteja sendo desenvolvida por alguma instituição ou ONG em prol das abelhas. 5) $O$ aluno deve reflitir sobre quais ações poderia realizar para contribuir na conservação desses insetos, caso se interesse. 


\section{Resultados e Discussão}

Repercussão dos questionários aplicados a alunos do ensino médio do estado do Rio de Janeiro.

A maior parte dos 50 alunos conseguiu responder grande parte do questionário, porém houve um percentual mais elevado de mulheres capazes de responder três ou mais perguntas, enquanto os homens obtiveram uma média inferior de respostas (Figura 1). Foi possível, no entanto, obter maior eficiência na análise devido a ampla quantidade de respostas totalizada.

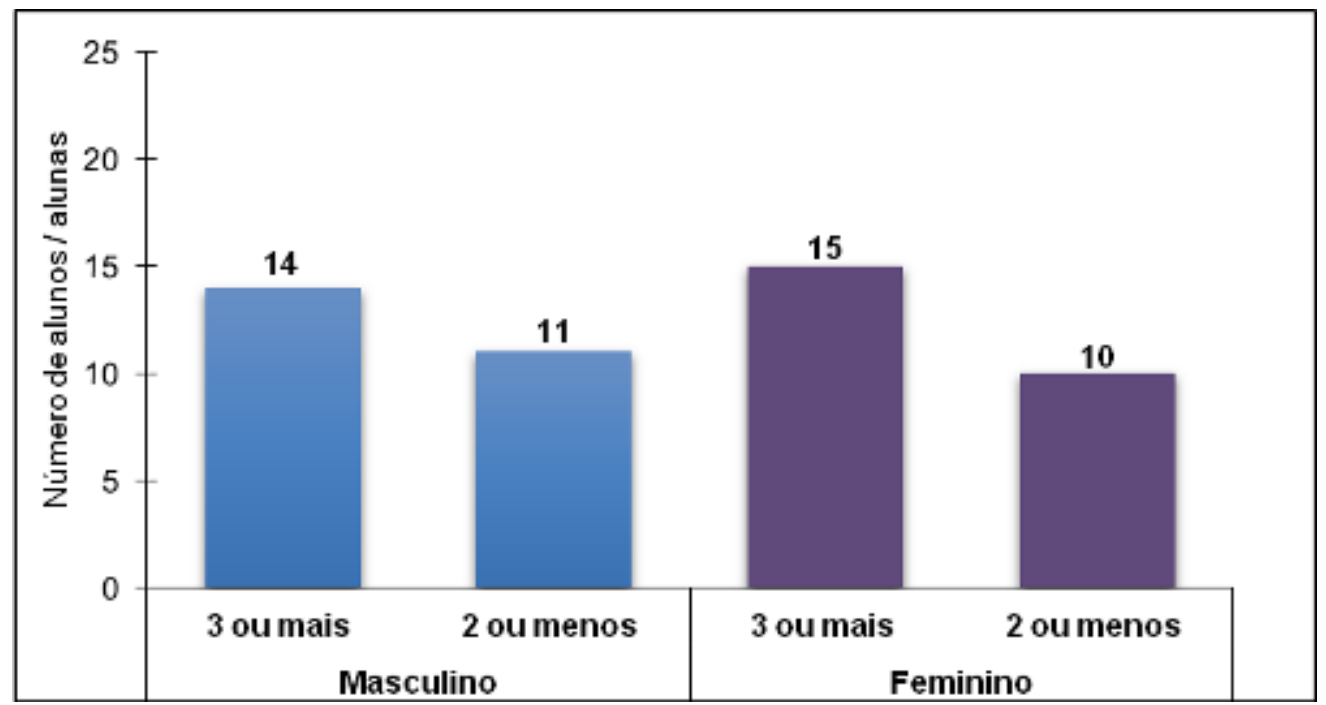

Figura 1: Quantidade de perguntas respondidas.

Fonte: os autores.

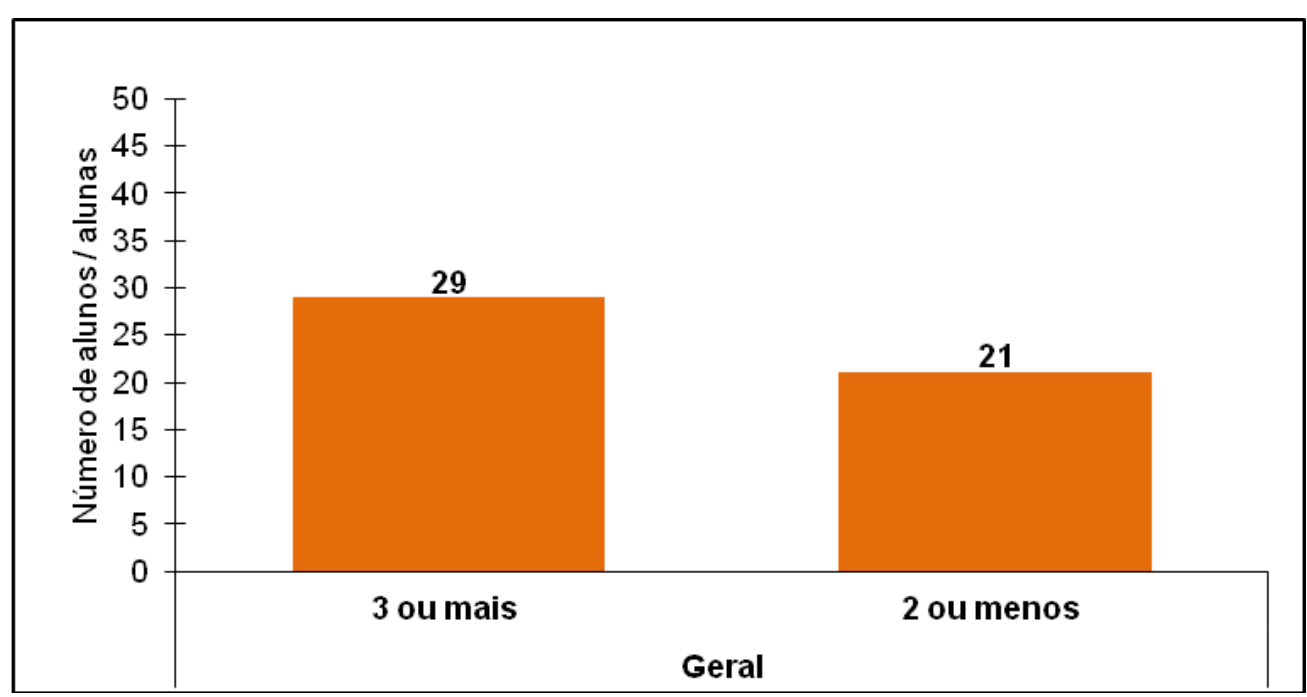

Figura 2: Quantidade de perguntas respondidas.

Fonte: os autores.

Revbea, São Paulo, V. 13, № 3: 263-274, 2018. 
Ainda que a maior parte dos entrevistados tenha respondido quase todas as perguntas do questionário, o índice de perguntas com duas ou menos respostas foi bastante elevado (Figura 2). Isto indica que alguns dos entrevistados têm falta de conhecimento, ou interesse, no tema abordado.

A maioria dos entrevistados indicou mosquitos como os insetos mais frequentemente encontrados e, no extremo oposto, as abelhas (Figura 3). Tal fato pode ter ocorrido devido aos últimos acontecimentos ligados à doenças (Dengue, Chikungunya e Zika Vírus) transmitidas por mosquitos, principalmente o Aedes Aegypti.

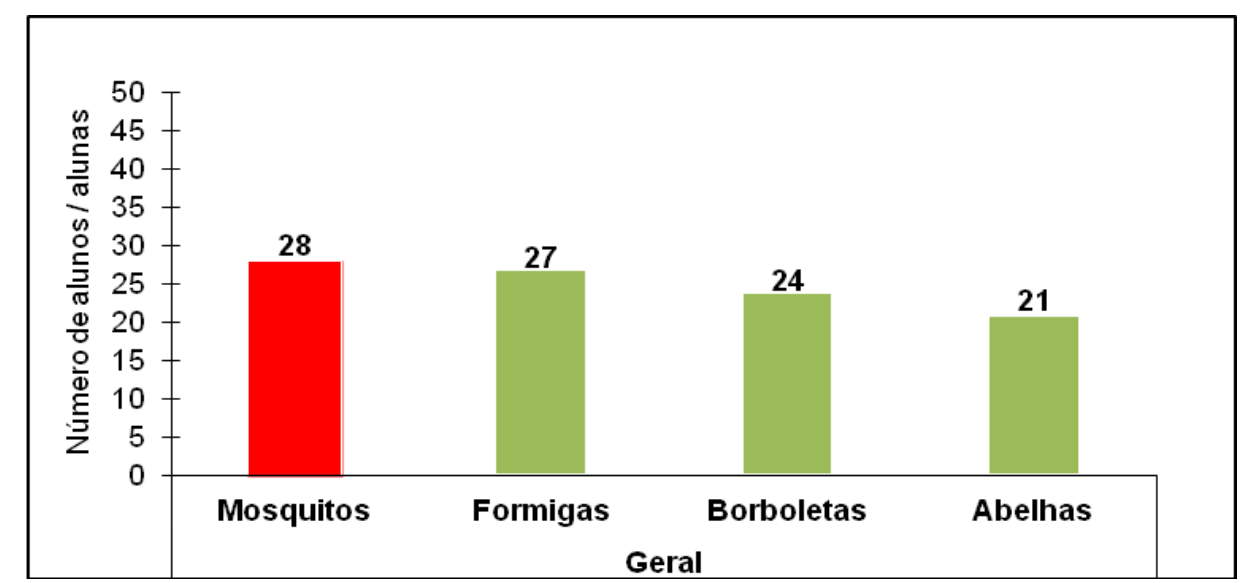

Figura 3: Insetos indicados como os mais frequentemente encontrados em jardins.

Fonte: os autores.

Ocorre que mesmo que todos sejam alunos do ensino médio, onde teóricamente possuem alguma base de ensino sobre ciências e/ou biologia, ainda há estudantes que não sabem reconhecer estes insetos. Alguns educandos não sabiam da existência de diferenças morfológicas entre espécies de abelhas, ou seja, a maioria se limitou às características de abelhas comuns, principalmente a abelha de mel Apis Mellifera e/ou abelhas sociais sem ferrão (Figuras 4 e 5).

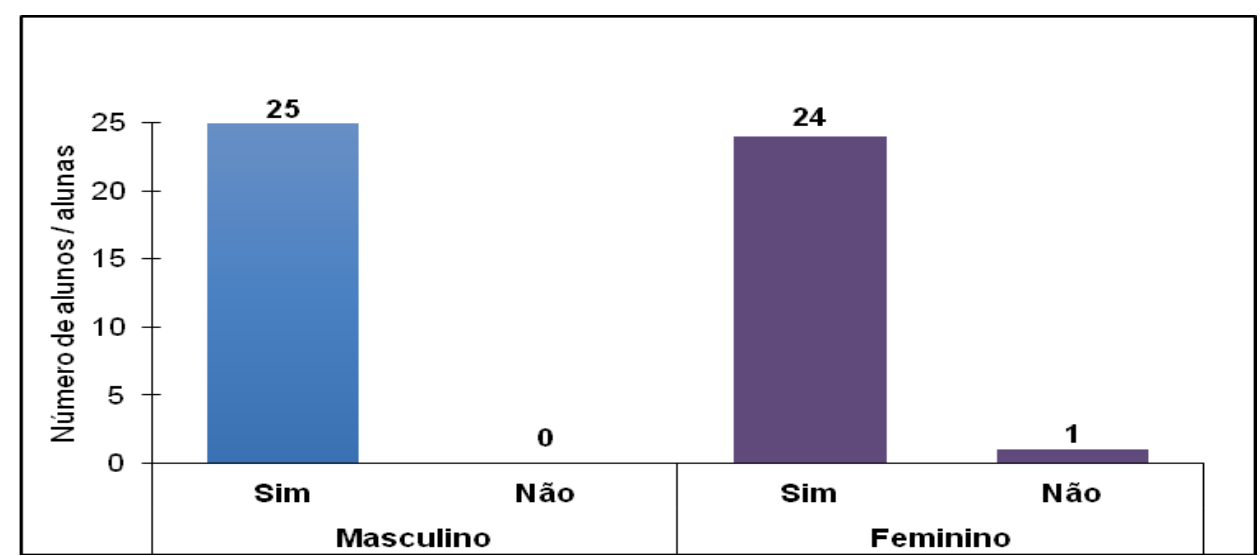

Figura 4: Saberiam reconhecer uma abelha?

Fonte: os autores. 
No universo mostrado, apenas um aluno não soube reconhecer uma abelha (Figura 5). Talvez a falta de interesse ou de atenção à pergunta tenha sido a causadora da resposta negativa. Porém, o número de alunos que sabe reconhecer uma abelha é bastante considerável. Ou seja, praticamente todos sabem identificar esse inseto.

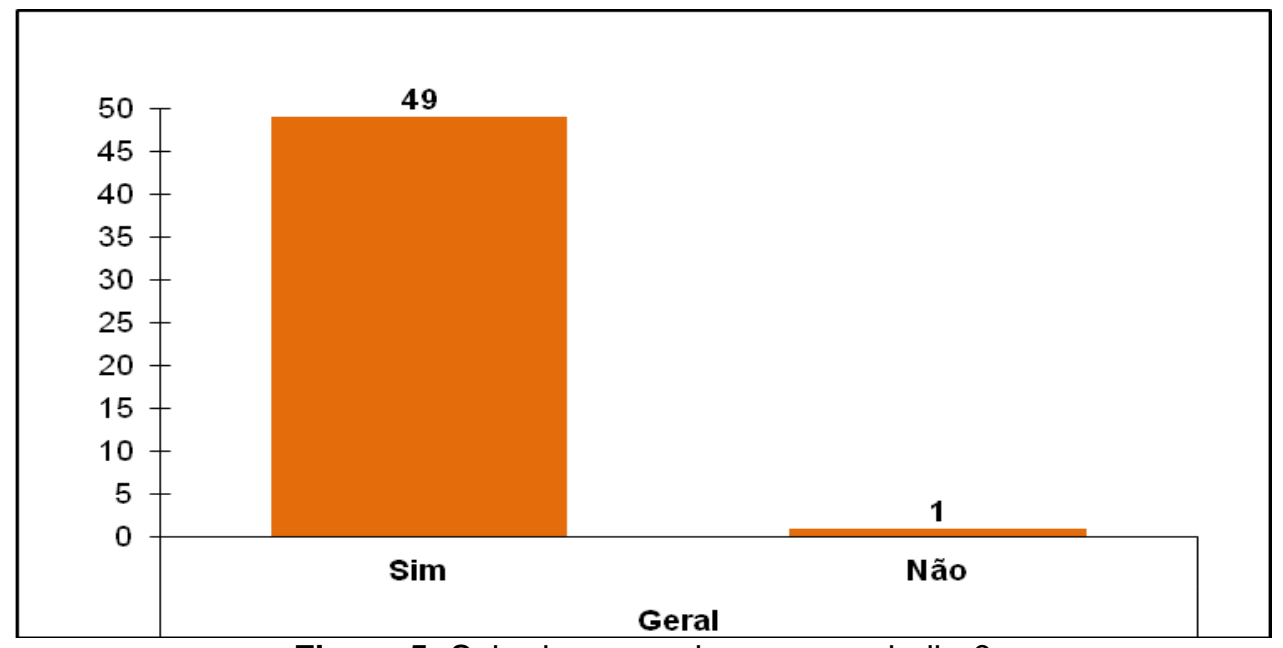

Figura 5: Saberiam reconhecer uma abelha?

Fonte: os autores.

A maior parte desse grupo de estudantes acha as abelhas importantes para o equilíbrio ecológico (Figuras 6 e 7). No entanto, existe um alto índice quantitativo que não considera essa importância relevante. A falta de interação dos entrevistados sobre assuntos ligados à ecologia de espécies é bastante nítida.

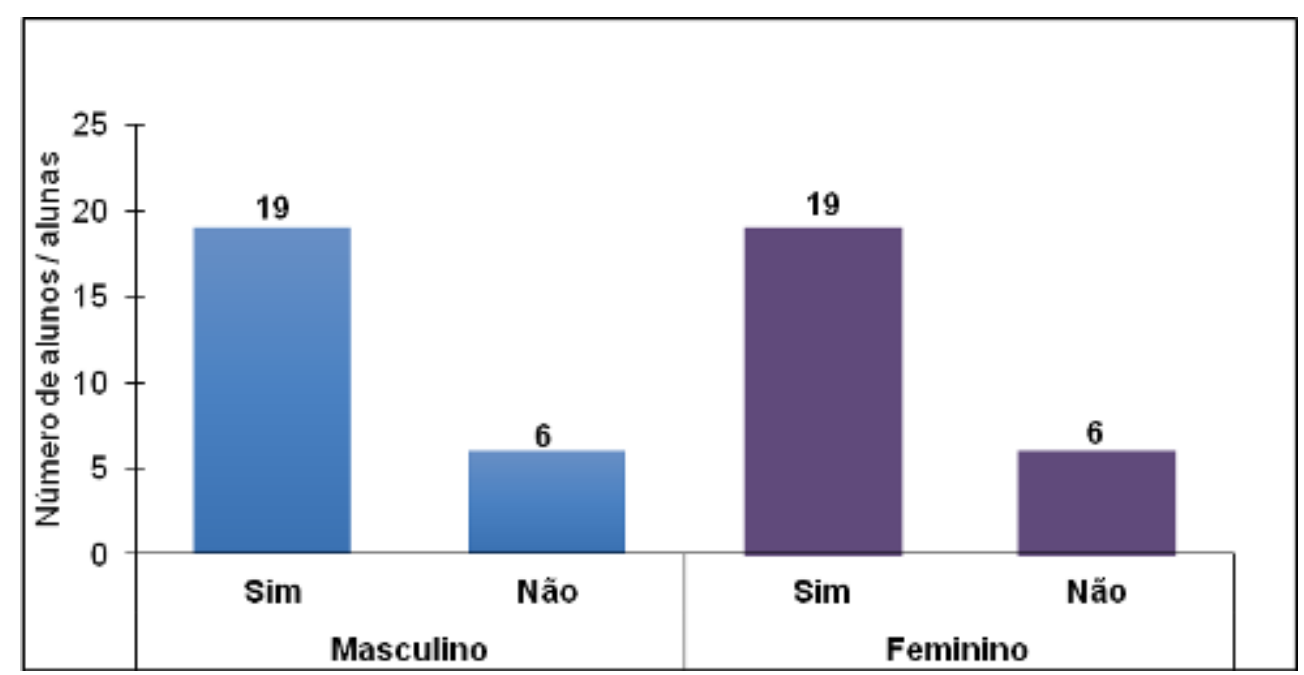

Figura 6: Reconhece a importância das abelhas para o equilíbrio ecológico?

Fonte: os autores.

Revbea, São Paulo, V. 13, № 3: 263-274, 2018. 
O resultado geral é considerado preocupante, pois $24 \%$ dos alunos alegam não reconhecer a importância da abelha para o equilíbrio ecológico (Figura 7).

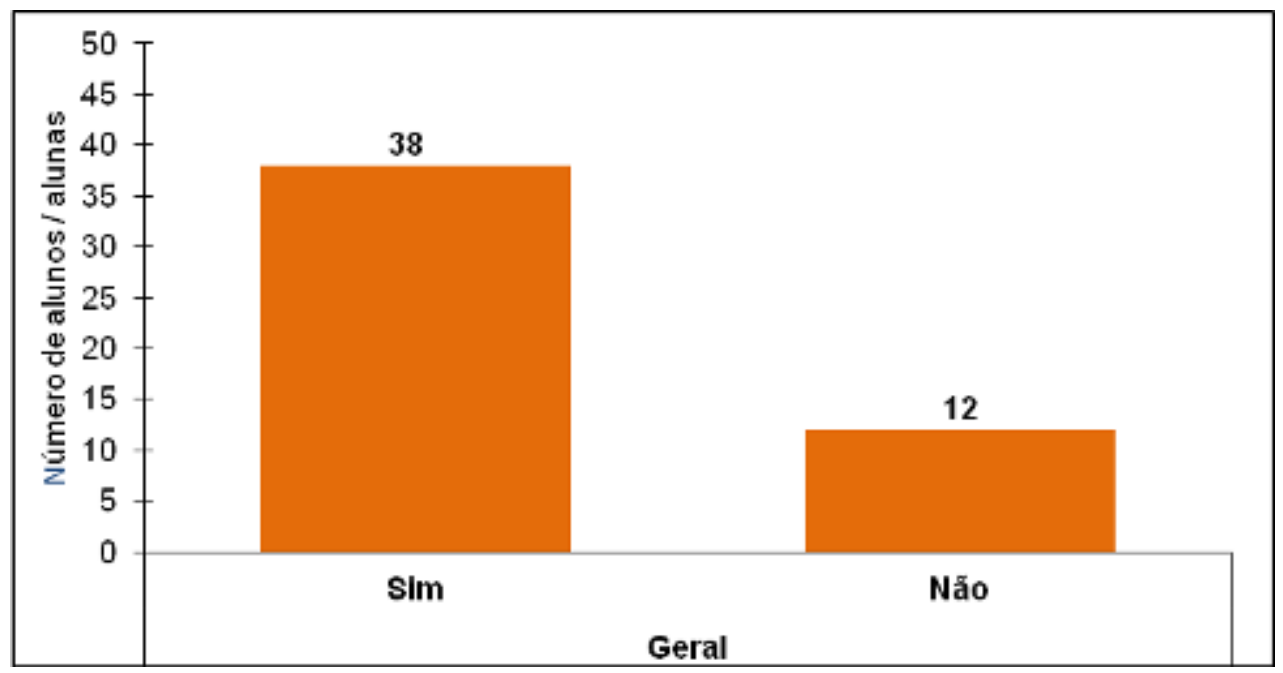

Figura 7: Reconhece a importância das abelhas para o equilíbrio ecológico? Fonte: os autores.

Quase todos os entrevistados indicaram não conhecer nenhum movimento, ou campanha, em prol das abelhas - embora realmente existam alguns (Figura 8). Este resultado evidencia um problema de difusão das campanhas que vêm sendo propostas em diferentes canais e redes sociais para o cuidado e preservação das abelhas.

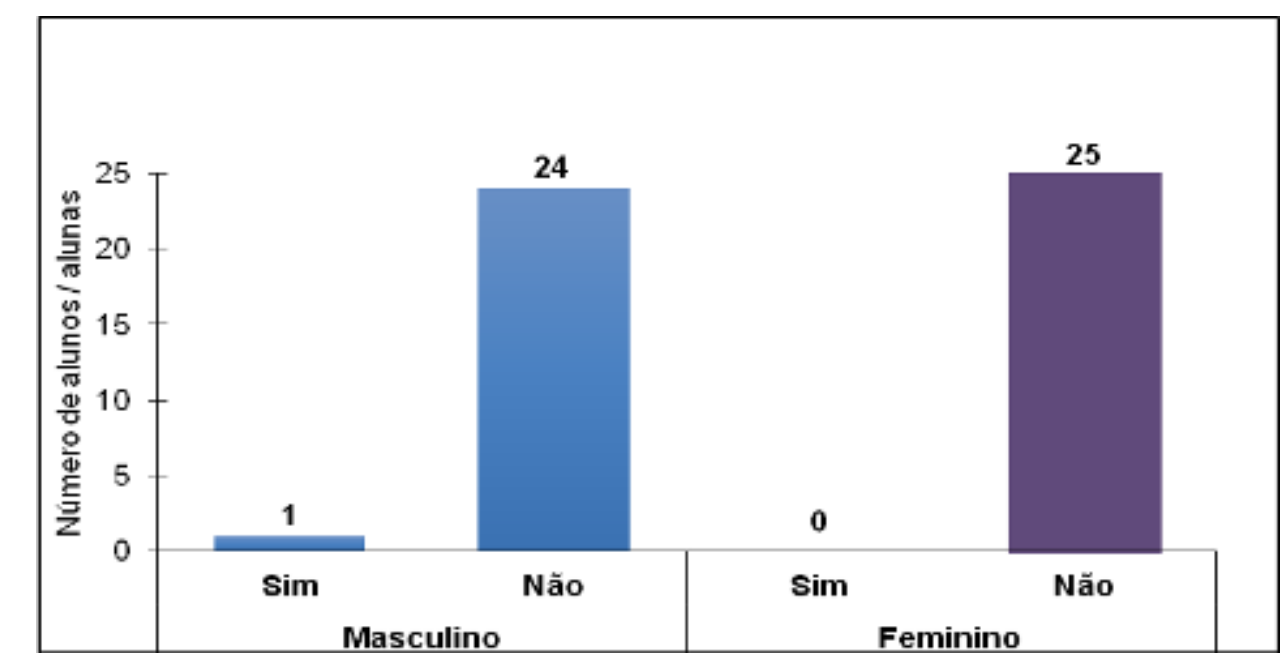

Figura 8: Conhecem algum movimento ou campanha em prol da conservação das abelhas? Fonte: os autores. 
Apenas um aluno conhece algum movimento, ou campanha, em prol das abelhas (Figura 9). Fato preocupante, pois trata-se de um inseto que possui grande importância para a ecologia de um determinado meio.

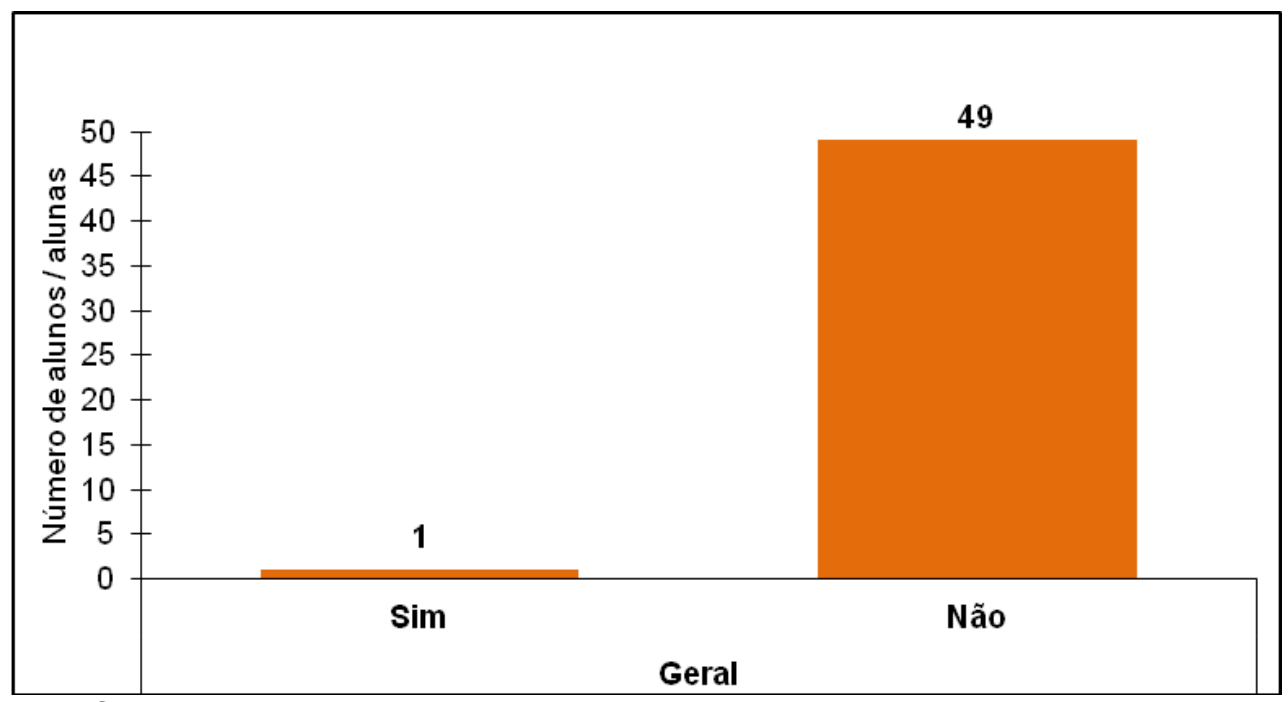

Figura 9: Conhecem algum movimento ou campanha em prol da conservação das abelhas?

Fonte: os autores.

Os resultados obtidos são negativos, pois grande parte dos entrevistados não faz qualquer atividade para conservar as abelhas, ainda que muitos afirmem reconhecer a importância delas para o equilíbrio ecológico (Figuras 10 e 11). Em decorrência desse resultado, podemos constatar que a falta de preservação gera um grande risco à ecologia de um meio.

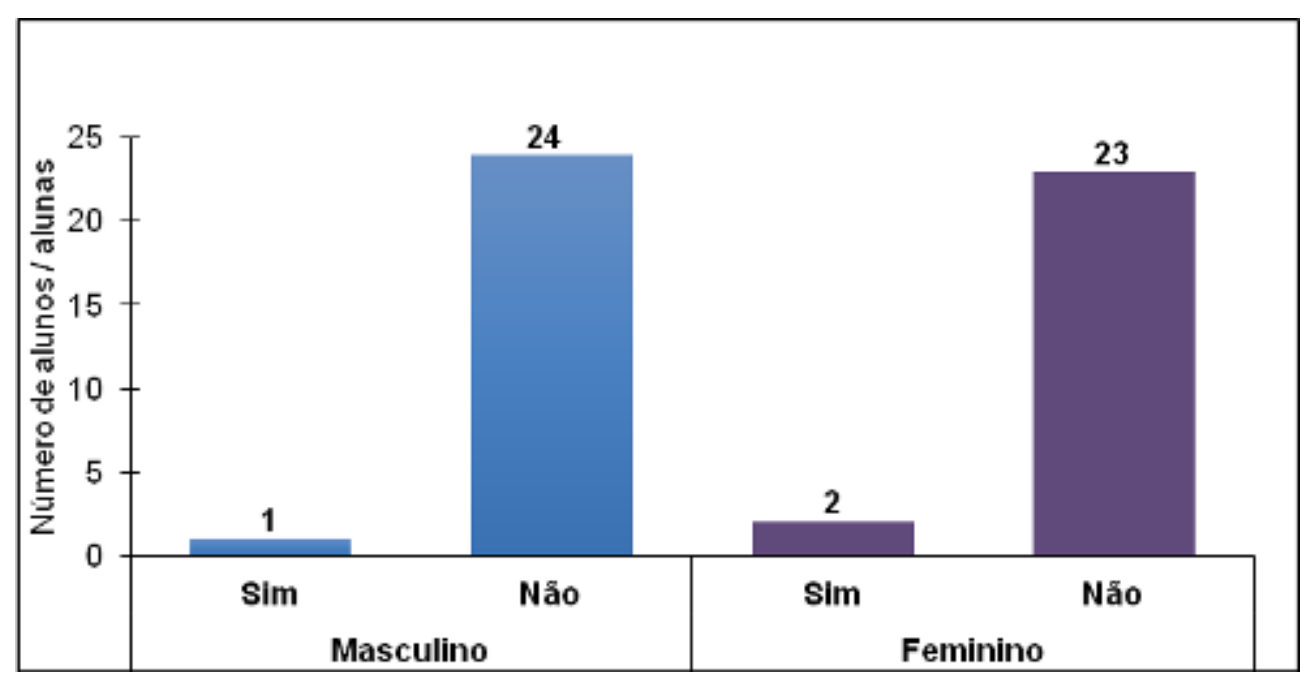

Figura 10: Fazem alguma atividade para conservação das abelhas?

Fonte: os autores. 


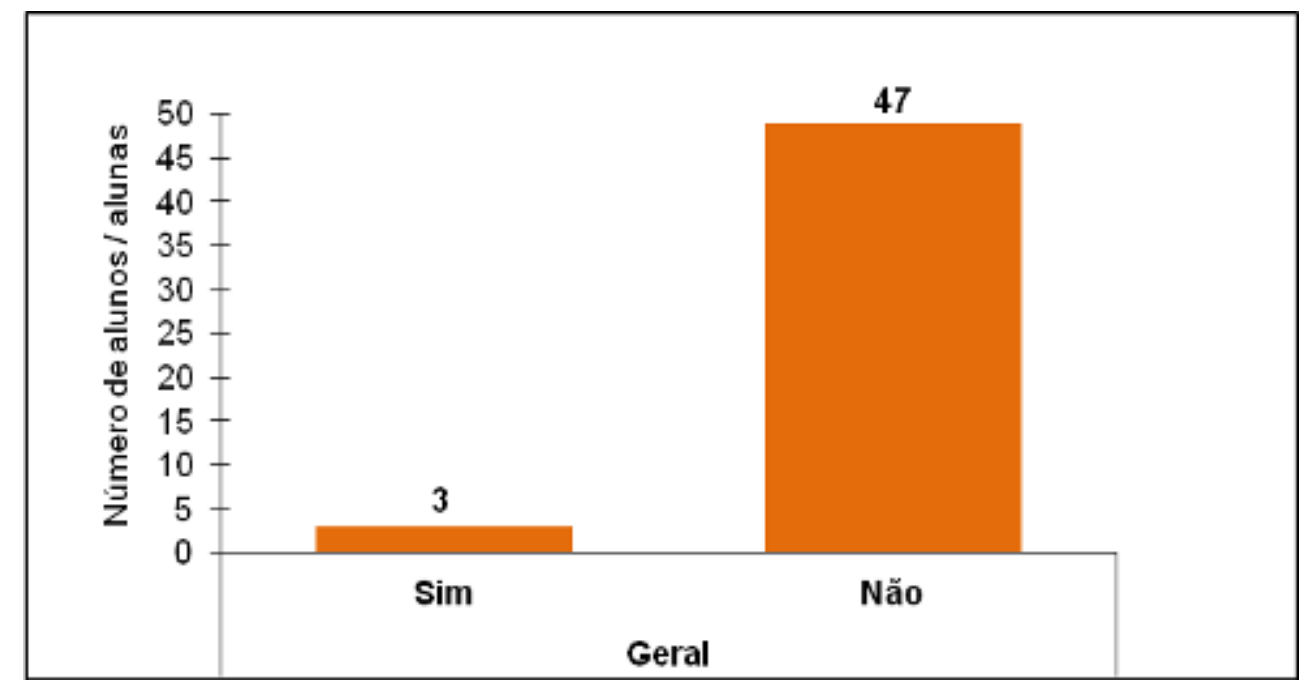

Figura 11: Fazem alguma atividade para conservação das abelhas?

Fonte: os autores.

Pode-se afirmar que mais de $94 \%$ dos entrevistados não faz nada para a conservação das abelhas, ou seja, existe uma grande deficiência de conscientização da população no que se refere a conservação desses insetos.

Segundo Guimarães (2004), a Educação Ambiental deve ser um processo contínuo e permanente, que se estenda por todas as etapas da educação formal ou informal. Nesse sentido, se essas questões tivessem mais ênfase em sala de aula, seria possível que os educandos tivessem desde o início de sua formação um conhecimento mais concreto sobre o desenvolvimento sustentável, a consciência ecológica, ou mesmo os benefícios que poderíamos ter com a manutenção de espécies. Porém os métodos de ensino inseridos durante a formação de alunos, como por exemplo, aqueles aprendidos no ensino médio, parecem ser bastante deficientes em tal aspecto. A falta de debates sobre a conservação dos seres vivos, ou atividades práticas relacionadas a isso, é grave. Muitos docentes acabam propondo o método de ensino tradicional, limitando o aluno a absorver mais informações sobre assuntos coligados à ecologia. O trabalho com meio ambiente em escolas traz à instituição a necessidade de estar preparada para este serviço junto aos professores (MEDEIROS et al., 2011).

Pode-se afirmar que poucos são os alunos que mostram algum tipo de conhecimento sobre o comportamento e importância de seres vivos encontrados com relativa frequência no dia a dia. A falta de posicionamento sobre tal assunto gera constantes conflitos entre a interação da sociedade para com o meio ambiente e os seres vivos encontrados nele.

Segundo Kearns et al. (1998), a conservação das abelhas, juntamente com outros polinizadores, é bastante preocupante já que elas são consideradas mantenedoras da biodiversidade através dos serviços prestados às 
comunidades florísticas de todo o mundo, via polinização (REGO; ALBUQUERQUE, 2006).

O estudo voltado para medir a interação do homem para com as abelhas foi bastante significativo, pois foi possível detectar onde se encontram os reais motivos que levam a sociedade a ter atitudes e opiniões equivocadas sobre esses polinizadores.

Os gráficos demonstraram nitidamente o parco conhecimento dos estudantes sobre assuntos ligados às abelhas. Um dos exemplos vem através da questão de número três (Figuras 4 e 5), onde foi abordada a pergunta "Você saberia reconhecer uma abelha?". A maioria dos entrevistados declarou saber reconhecer, porém relacionam o inseto a características de uma única espécie (abelha de mel), o que demonstra um alto grau de limitação nas respostas do questionário.

A criação de algumas metodologias de ensino e conscientização é de grande ajuda, pois possibilita que a comunidade consiga se integrar mais com assuntos ligados à preservação e ecologia desses insetos. Através disso, para aproximar os alunos com assuntos relacionados à conservação das abelhas, poderiam ser oferecidas palestras com imagens ilustrativas e explicativas sobre esses polinizadores. As palestras poderiam ser direcionadas a estudantes do ensino fundamental e médio, assim como ao público leigo.

Segundo Valente e Matar (2007), o uso da tecnologia no ambiente virtual propicia uma viagem em busca do conhecimento, permitindo ao aluno uma forma diferente de participação. Ele não estaria limitado somente a ver imagens, mas poderia também vivenciar o espaço em que a experiência está ocorrendo e aprender. Assim, a elaboração de sites e blogs de divulgação com abordagens simples e informativas de assuntos relacionados à manutenção das abelhas seria de grande ajuda para difundir a importância destes insetos no ambiente, mostrando, por exemplo, imagens de espécies de abelhas nativas do Brasil, com dicas que contribuiriam para a manutenção das populações destes polinizadores; tais como: o cuidado com as flores, formas de como cultivar plantas com flores em vasos ou canteiros, fomentar a não utilização de defensivos agrícolas tóxicos para as abelhas, incentivar e educar às pessoas para que não cortem flores, ou destruam jardins ou áreas de nidificação, etc.

\section{Conclusões}

Foi possível evidenciar, através das metodologias aplicadas, a falta de informações da maioria dos alunos entrevistados sobre assuntos básicos ligados às abelhas.

É notório que a preservação desses insetos polinizadores é importante, porém a falta de conscientização de muitos prejudica o andamento de ações voltadas à conservação das abelhas. 
Esses resultados obtidos reforçam a necessidade de existências de mais canais de informação que reforcem, não só a importância da preservação das abelhas, mas também de todos os animais que realizam direta, ou indiretamente, a polinização.

As ferramentas acessíveis em favor das abelhas são de fácil alcance, possibilitando que esses insetos consigam realizar e incrementar suas atividades ecológicas com pequenas alterações na rotina diária das pessoas, trazendo grandes benefícios na manutenção de muitos ecossistemas terrestres.

\section{Agradecimentos}

Ao Dr. Rodrigo de Oliveira Araujo da Universidad Católica del Maule, Chile, pelas suas sugestões durante a realização desta pesquisa. Este artigo é parte do projeto SIGMA №21565 MN/UFRJ e a contribuição número 31 do HYMN Laboratório de Hymenoptera do Museu Nacional/ Universidade Federal do Rio de Janeiro.

\section{Referências}

ARRAIS, L. C. A questão ambiental na escola. 2011. Disponível em: http://www.webartigos.com/artigos/a-questao-ambiental-na-escola/67632/. Acessado em 06 de abril de 2016. Acessado em 06 de abril de 2016.

CAIXETA, D. A.; ROMEIRO, A. R. Serviços ecossistêmicos e sua importância para o sistema econômico e o bem-estar humano. Texto para Discussão. IE/UNICAMP, Campinas, n. 159, p. 01-24, mai., 2009.

ENGELSDORP, D.; HAYES, JÚNIOR.; UNDERWOOD, R. M.; PETTIS, J. S. A survey of honey bee colony losses in the U.S., Fall 2007 to Spring 2008. PLoS ONE, San Francisco, v.3, n. 12, p. 40-71, dez., 2008.

FARID, A. A. et al. MILLENNIUM ECOSYSTEM ASSESSMENT. Ecosystem and human well-being: Synthesis. Washington, DC: Island Press, 2005.

FREITAS, B. M.; IMPERATRIZ-FONSECA, V. L.; MEDINA, L. M.; KLEINERT, A. M. P.; GALETTO, L.; NATES-PARRA, G.; QUEZADA-EUÁN, J. J. G. Diversity, treats and conservation of native bees in the Neotropics. Apidologie, v. 40, p. 332-346, mai., 2009.

GUIMARÃES, M., et al. Educadores ambientais nas escolas: As redes de estratégia. Caderno CEDES, Campinas, v. 29, n. 77, p. 49-62, jan./abr., 2009.

KEARNS C. A; INOUYE D. W; WASER, N. Endangered mutualisms: The Conservation of Plant-Pollinators Interactions. Annual Review of Ecology and Systematics, v. 29 n.1, p.83-112, nov., 1998.

KLEIN, A. M.; VAISSIÈRE, B. E.; CANE, J. H.; STEFFAN-DEWENTER, I.; CUNNINGHAM, S. A.; KREMEN, C.; TSCHARNTKE, T. Importance of pollinators 
in changing landscapes for world crops. Proceedings of the Royal Society of London Series B - Biological Sciences, London, v. 274, p. 303-313, fev., 2007. LAURENT, M.; HENDRIKX, P.; RIBIERE-CHABERT, M.; CHAUZAT, M.-P. A pan-European epidemiological study on honeybee colony losses 2012-2014. 2015.2 Disponível em: https://ec.europa.eu/food/animals/live animals/bees/health en. Acesso em: 02 de abril de 2016.

MEDEIROS, B. A.; MENDONÇA, L. S. M.; SOUZA, L. G.; OLIVEIRA, P. I. A importância da Educação Ambiental na escola de series iniciais. Revista Faculdade Montes Belos, v. 4, n. 1, set. 2011.

MICHENER, C. D. The Bees of the World. $2^{\text {nd }}$. Johns Hopkins University Press, Baltimore, 2007.

NOCELLI, R. C. F.; MALASPINA, O.; CARVALHO, S. M.; LOURENÇO, C. T.; ROAT, T. C.; PEREIRA, A. M.; SILVA-ZACARIN, E. C. Polinizadores do Brasil. Contribuição e perspectivas para a biodiversidade, uso sustentável, conservação e serviços ambientais. 2015. Disponível em: http://myrtus.uspnet.usp.br/statuspolin/13.html. Acesso em: 06 de abril de 2016.

ORLANDINI, E. A. Consciência ambiental e a falta da sua prática efetiva. 2009. Disponível em: http://www.webartigos.com/artigos/consciencia-ambientale-a-falta-da-sua-pratica-efetiva/25359/. Acessado em: 04 de abril de 2016.

PHILIPPI JR. A.; PELICIONI, M. C. Educação Ambiental e sustentabilidade. 2.ed. Barueri: Manole, 2005.

RÊGO, M.; ALBUQUERQUE P. Polinização do Murici. São Luís: Ed. UFMA, 2006

ROUBIK, D.W. Nest and colony characteristics of stingless bees from French Guiana (Hymenoptera: Apidae). Journal of the Kansas Entomological Society, v. 52, n.3, p. 443-470, 1979.

SOUZA, L.; EVANGELISTA, R. A.; PINTO, M. S. C. As abelhas como agentes polinizadores (The bees agentes pollinizer's) REDVET. Revista Electrónica de Veterinária, v. 8, n. 3, p. 03, mar., 2007.

VALENTE, C.; MATTAR, J. Second Life e Web 2.0 na educação: o potencial revolucionário das novas tecnologias. São Paulo: Novatec Ed., 2007. 